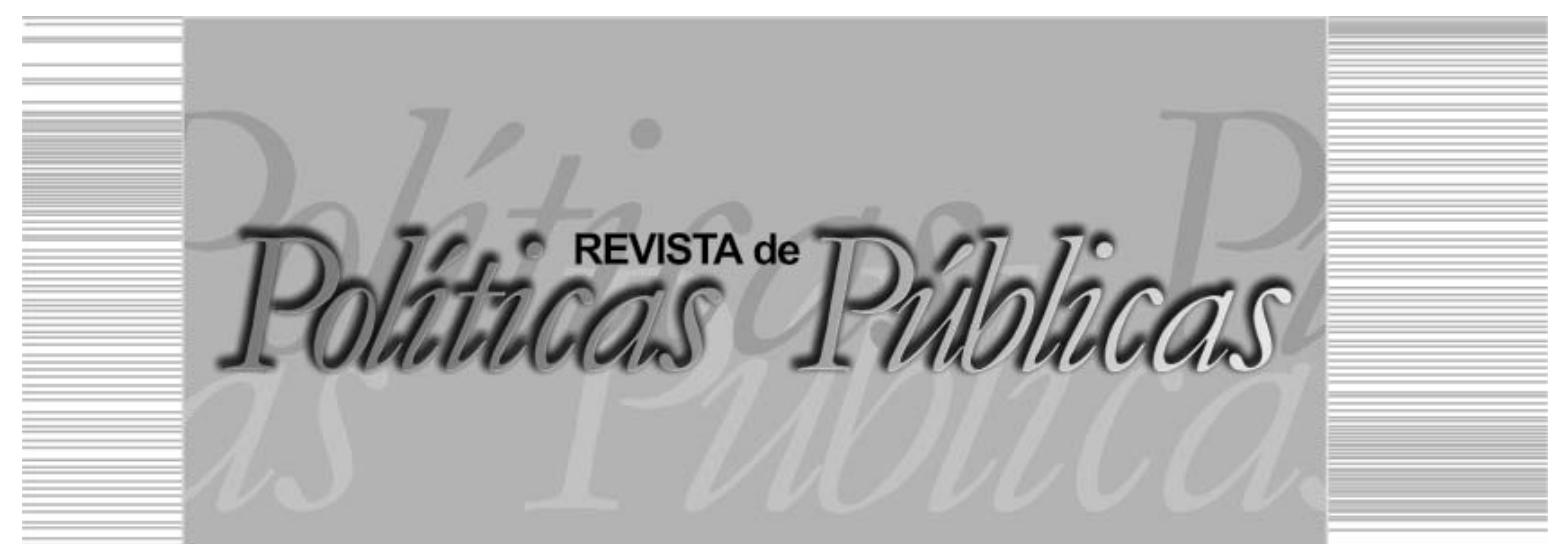

\title{
SUPEREXPLORAÇÃO DA FORÇA DE TRABALHO E PREVIDÊNCIA SOCIAL NA AMAZÔNIA
}

Christiane Pimentel e Silval

Universidade Federal do Pará (UFPA)

\section{Resumo}

O artigo discute os mecanismos de exploração e superexploração da força de trabalho, no pensamento de Karl Marx e de Ruy Mauro Marini, para compreender o acesso dos trabalhadores à proteção social, especialmente a Previdência social. Destaca as formas específicas de inserção da força de trabalho na Amazônia, tanto ao trabalho quanto à previdência, a partir de indicadores sociais e conclui que a superexploração constitui barreiras estruturais à consolidação da proteção social universal, incluindo a previdência social, que no contexto amazônico ainda é acirrado pela sua forma de inserção ao capitalismo.

Palavras-chave: Superexploração, proteção social, Previdência Social, Amazônia.

\section{Abstract}

The article discusses mechanisms of exploration and overexploration of the working classe, based mainly in the theory of Karl Marx and Marini, to understand workers' access to social protection, especially Social Security. Noteworthy is the specific forms of integration of the labor force in the Amazon, both at work and to social security, from social indicators and concluded that overexploration is structural barriers to consolidation of universal social pro-

\footnotetext{
Assistente Social. Mestre em Serviço Social pela Universidade Federal do Pará (UFPA). Professora da Faculdade de Serviço Social no Campus do Marajó-Breves da UFPA. E-mail: chrissilva@linuxmail.org | Universidade Federal do Pará - UFPA | Alameda IV, no 3418, Parque Universitário - Breves-PA | CEP: 68.800-000
} 
tection, including social security, which in the Amazon region is still strained by its form of incorporation to capitalism.

Key words: Overexploration, social protection, Social Security, Amazon.

\section{INTRODUÇÃO}

Este artigo visa compreender o contexto contemporâneo em que se dinamizam as relações de superexploração da força de trabalho na Região Amazônica e seus desdobramentos para a previdência social, apoiado nas categorias exploração e superexploração da força de trabalho, respectivamente, de Marx (2008) e de Marini (1990), que desvelam as determinações estruturais do capital que produzem a pauperização da classe trabalhadora.

Destaca-se a contemporaneidade das categorias para a análise da situação de vida da classe trabalhadora e de acesso a políticas de proteção social, principalmente a previdência social. A ênfase não consiste apenas em retratar as condições de vida e de superexploração, que repercutem na universalidade do sistema protetivo, mas principalmente, relacionar as mediações entre a superexploração e as fragilidades do sistema de proteção social brasileiro e, ainda, o acirramento destas contradições na Amazônia.

\section{NOTAS SOBRE EXPLORAÇÃO E SUPEREXPLORAÇÃO DA FORÇA DE TRABALHO}

Marx (2008) explica que o ato humano de transformar a naturalidade, numa ação de regulação e controle das propriedades da natureza, é um processo que visa uma finalidade: objetiva adaptar a matéria natural às necessidades humanas. Este vínculo orgânico do ser social com a natureza é sua base fundante, pois no ato de trabalho estão presentes a resposta dada às necessidades reais, a partir do estudo da natureza dada, a aquisição de novas habilidades e destrezas, a orientação para uma determinada finalidade, a projeção de todo o processo antes de sua execução, o ato em si de trabalho, a utilização de meios que possibilitam essa mediação entre o homem e a natureza, assim como também, quando se considera a reprodução do ato de trabalho, podemos citar a transmissão do conhecimento adquirido e seu contínuo aperfeiçoamento pelo ser social.

Como o trabalho se volta às necessidades sociais concretas, seu resultado é a própria riqueza social, que no modo de produção burguês se converte em atividade essencial que é vendida como mer- 
cadoria. Os trabalhadores são despojados de seus meios de trabalho e não encontram outra maneira de garantir sua existência sem a venda de sua força de trabalho aos proprietários dos meios de produção, os capitalistas.

A força de trabalho é uma mercadoria essencial ao capital, porque além de dar forma aos objetos úteis à vida humana, imprimindo-lhes valor (de troca), é a única que produz mais-valia, ou seja, durante o processo produtivo, acresce um valor superior que é apropriado pelo capitalista. Isso ocorre porque no processo de trabalho, a jornada de trabalho contém um prolongamento além do tempo necessário para a reprodução da força de trabalho ${ }^{1}$ (MARX, 2008).

Este prolongamento da jornada de trabalho constitui um período de tempo denominado por Marx (2008) de trabalho excedente, e se caracteriza pelo fato de o trabalho continuar, desde o momento inicial até o final da jornada, sem o equivalente em valor, ou seja, o trabalhador prossegue a produção de mercadorias, gerando um produto excedente que será vendido junto com os demais e que constituirá mais-valor ao capital.

A partir da análise da obra de Marx, Silva (2010) refere que com o recuo das barreiras naturais, a partir do aumento da força produtiva (meios e/ou métodos de trabalho) que produz uma alteração no próprio processo de trabalho em geral, se produz uma mais-valia relativa, obtida por meio da diminuição do tempo de trabalho necessário, modificando a proporção entre os dois componentes da jornada de trabalho.

A mais-valia relativa é possível porque de maneira geral, as condições técnicas ${ }^{2}$ e sociais do processo de trabalho alteram os ramos produtores dos meios de subsistência dos trabalhadores, barateando aquelas mercadorias e, assim, afetando a determinação do valor da força de trabalho por meio de sua redução. Segundo a síntese de Silva (2010, p. 51), o conceito de mais-valia reúne:

1) o prolongamento da duração da jornada de um mesmo processo
de trabalho; 2) a mais-valia é a própria exploração da força de tra-
balho, um dispêndio excessivo da força de trabalho; 3 ) o entendi-
mento do excedente sobre o valor original que altera na circulação
sua grandeza de valor; 4) esse movimento transforma a mais-valia
em capital; e 5) a expansão do capital é realizada pela extração da
mais-valia, ou seja, a mais-valia é um imperativo ou uma impo- 
sição objetiva do capital, sem esta não há continuidade no ciclo capitalista de produção.

A contínua expansão do capital no impulso de sua autovalorização conduz a uma ampliação das relações capitalistas entre os diversos países e regiões e, nesse marco conceitual, Marini (1990) compreende que a inserção da América Latina ao mercado mundial contribui para a reprodução do capitalismo, para que nos países centrais, ocorra a incorporação da mais-valia relativa, ou seja, a produção latino-americana possibilita a redução real do valor da força de trabalho nos países imperialistas.

Nesses países, a acumulação de capital se baseia na produtividade do trabalho em conjunto com a redução do valor da força de trabalho, e isto significa que o consumo individual dos trabalhadores auxilia na criação de demanda das mercadorias produzidas.

Nos países dependentes, as demandas produtivas não são interiores à produção; se produz com o objetivo primário de exportar, criando uma separação entre a esfera da circulação e a esfera produtiva. Como no capitalismo dependente a industrialização não cria sua demanda, mas apenas atende uma demanda preexistente dos países imperialistas, parte dos excedentes gerados nos primeiros é transferido para os centros, provocando uma expropriação do valor, que é compensada na esfera produtiva (MARINI, 1990).

A contradição nestes mecanismos de transferência de valor compromete a realização da taxa de mais-valia ${ }^{3}$ e a resposta para superar este obstáculo à concretização da taxa de lucro é a constituição de uma tendência à superexploração da força de trabalho, cujas principais características, definidas por Marini (1998, p. 110) são:

\begin{abstract}
a) não garante a reprodução normal da força de trabalho; b) assume a forma enganadora de mais-valia relativa (ao contrário do que supõe a maioria dos autores que se referem à questão), pois, mantendo-se invariável a jornada, se reduz aparentemente o tempo de trabalho necessário; c) não se confunde com o conceito de mais-valia extraordinária, ou seja, a que o capitalista individual obtém em proporção superior a seus concorrentes, ao reduzir o tempo de produção de sua mercadoria, mas não seu valor (uma vez que o valor da mercadoria se estabelece de acordo com as condições gerais, e não individuais, de produção).
\end{abstract}

Isto significa que nos países dependentes, o valor da produção exportadora não reflete o valor da força de trabalho, e, assim, o 
capitalista não visa desvalorizar a força de trabalho com o auxílio do aumento da força produtiva, ou seja, pelo acréscimo da taxa de mais-valia, mas sim pelo aumento da massa de valor (apenas mais-valia), o que pressupõe uma extrema exploração da força de trabalho.

Outra consequência relevante da superexploração da força de trabalho nas economias exportadoras, refere-se ao fato de que por um lado, a compressão salarial dos trabalhadores abaixo de seu valor concreto, não afeta a esfera da circulação na medida em que se realiza em base internacional; por outro lado, a capacidade extremamente diminuta de consumo da força de trabalho se constitui como obstáculo ao investimento nos setores de produção de consumo popular.

O resultado, para Marini (1990), é um desgaste prematuro da força de trabalho, ignorado pelo capital, em virtude da facilidade de sua reposição, possível pelo aumento de força trabalhadora disponível, dinamizado também pelos constantes fluxos migratórios. Além disso, se o capitalismo dependente não restitui o valor da força de trabalho, há uma forte concentração de renda, mesmo quando ocorre a produção industrial de bens primários, esta corresponde a etapas inferiores da produção industrial e, em especial, dos meios de subsistência ${ }^{4}$.

\section{FORÇADE TRABALHO NAAMAZÔNIA E PREVIDÊNCIA SOCIAL DECORRENTE}

A inserção da força de trabalho da Região Amazônica ${ }^{5}$, frente a essa base subordinada ao capital, é compreendida por meio da hierarquização da economia capitalista, que se reproduz nas regiões do Brasil. Ainda que o país, como um todo, seja dependente, há um acirramento da superexploração da força de trabalho na Região Amazônica, que decorre da diversidade do grau de desenvolvimento das forças produtivas, imbricada na composição orgânica do capital $^{6}$, que determinam distintas formas e graus de exploração da força de trabalho.

Os dados estatísticos de 2014, da Confederação Nacional da Indústria $(\mathrm{CNI})$, demonstram que a distribuição das indústrias no Brasil em grandes regiões é: 1) Sudeste 46,91\%; 2) Sul 27,14\%; 3) Nordeste $13,54 \%$, em cujo percentual se excluiu o estado do Maranhão; 4) Centro-Oeste 6,21\%, com exceção do estado do Mato Grosso e; 5) Amazônia 6,21\%, considerada a partir dos sete estados da Região Norte e acrescida dos estados Maranhão e Mato Grosso. 
Mesmo considerando nove estados, a incidência da produção industrial na Amazônia é muito reduzida e, em parte, explica as relações de produção amazônicas.

A pequena incidência de indústrias na Região Amazônia, por um lado, apenas indica o diminuto emprego de métodos de economia de força de trabalho (em tempo e esforço físico), mas por outro lado, revela que mesmo as técnicas obsoletas de produção (nos países centrais) são incorporadas à acumulação de capital.

Além disso, a leitura de Marini $(1990,1998)$, permite a compreensão de que a lógica de acumulação do capital para a Região Amazônica não prioriza a redução da jornada necessária de trabalho, suprindo em parte a demanda de produção pelo consumo das classes intermediárias e proprietárias, sem a contrapartida da equivalência da reprodução das condições de existência do trabalhador.

O acentuado grau de exploração da força de trabalho na Amazônia deve-se à necessidade de recriar as condições de reprodução ampliada da dependência, ou seja, tem origem na inserção do Brasil à acumulação capitalista, mas ocorre por meio de formas inferiores de expropriação do valor.

As regiões Sudeste e Sul, ao utilizarem formas de produção industriais consideradas obsoletas, apesar de não eliminarem a dependência, diminuem o grau de exploração da força de trabalho em níveis intermediários. Enquanto que na Amazônia, para alcançar os níveis de produtividade exigidos pela demanda externa, sem a correspondente diminuição do tempo de jornada necessária, recorre-se ao maior emprego de uso extensivo e intensivo da força de trabalho, em que há maior dispêndio de força física do trabalhador.

Para Marini (1990), não apenas ocorre a restrição do mercado interno, mas também exclui a classe trabalhadora do consumo de bens supérfluos, gerando duas importantes contradições: 1) a constituição de uma imensa superpopulação relativa e 2) com a realização de bens supérfluos restrita a classes intermediárias e proprietárias, a reprodução do capital deve-se desdobrar para exportação não apenas de produtos essenciais, mas também de produtos supérfluos.

A Tabela 1, a seguir, nos permite observar que a Amazônia, com nove estados brasileiros, ainda é a região com menor número de empregos com vínculos trabalhistas; isso nos possibilita estimar que grande parte da população trabalhadora não possui vínculos por 
meio da carteira assinada e também que há uma enorme e crescente superpopulação relativa.

\begin{tabular}{|c|c|c|c|c|c|c|}
\hline \multirow[b]{2}{*}{ Espacialidade } & \multirow{2}{*}{$\begin{array}{c}\% \\
\text { trabalhadores } \\
\text { informais }\end{array}$} & \multicolumn{5}{|c|}{$\%$ trabalhadores por classes de rendimento } \\
\hline & & $\begin{array}{c}\text { Sem } \\
\text { rendimento }\end{array}$ & Até $1 / 4$ & $\begin{array}{c}\text { Mais de } 1 / 4 a \\
1 / 2\end{array}$ & \begin{tabular}{|c|} 
Mais de \\
$1 / 2$ a 1
\end{tabular} & \begin{tabular}{|r|} 
Mais de \\
$a \quad 2$
\end{tabular} \\
\hline Acre & 55.45 & 12.73 & 2.86 & 6.43 & 30.38 & 25.63 \\
\hline Amapá & 54.20 & 6.90 & 2,46 & 6.09 & 29.22 & 26.25 \\
\hline Amazonas & 56.44 & 13.51 & 3.28 & 5.92 & 27.22 & 28.08 \\
\hline Maranhão & 68.44 & 18.90 & 8.76 & 10.44 & 30.66 & 18.54 \\
\hline Mato Grosso & 48.59 & 5.86 & 1.37 & 3.72 & 23.32 & 35.28 \\
\hline Pará & 65.16 & 12.53 & 5.67 & 9.24 & 32.08 & 23.39 \\
\hline Rondônia & 53.59 & 9.91 & 2.28 & 5.54 & 24.54 & 31.31 \\
\hline Roraima & 54.02 & 11.82 & 1.66 & 4.19 & 31.74 & 23.87 \\
\hline Tocantins & 56.33 & 10.03 & 3.01 & 6.65 & 31.91 & 25.39 \\
\hline
\end{tabular}

Fonte: Elaborada pelo autor, a partir de: INSTITUTO BRASILEIRO DE GEOGRAFIA E ESTATÍSTICA Censo 2010. Rio de Janeiro, 2011.

Na Tabela 1, verifica-se que 1) apenas o estado do Mato Grosso não possui mais da metade de sua força de trabalho constituída por trabalhadores sem carteira assinada, conhecidos como trabalhadores informais e, entre estes estados, as situações mais agudas são encontradas no Maranhão (68\%) e no Pará $(65 \%) ; 2)$ uma elevada incidência de uma parte da classe trabalhadora que não recebe salário, ou seja, está ajudando a algum membro da família; e 3) entre os trabalhadores que recebiam salário, a absoluta maioria recebia até dois salários mínimos ${ }^{7}$, mas estados como Pará $(32 \%)$, Tocantins (31\%), Roraima (31\%), Acre (30\%) e Amapá (29\%), concentram sua força trabalhadora na faixa de rendimento mensal entre o valor de mais de $1 \frac{1}{2}$ (meio) a 1 (um) salário mínimo.

Este desenho é fundamental para compreender as condições de inserção dos trabalhadores amazônicos na Previdência Social, pois no Brasil, ela se configura a partir da filiação obrigatória e de caráter contributivo, de acordo com o art. 201 da Constituição Federal (CF) de 1988 e se destina a (BRASIL, 2015, p. 75):

\footnotetext{
II - cobertura dos eventos de doença, invalidez, morte e idade avançada;

II - proteção à maternidade, especialmente à gestante;

III - proteção ao trabalhador em situação de desemprego involuntário;

IV - salário-família e auxílio-reclusão para os dependentes dos segurados de baixa renda;
} 
$\mathrm{V}$ - pensão por morte do segurado, homem ou mulher, ao cônjuge ou companheiro e dependentes [...].

A Previdência Social é compreendida, inicialmente, como uma política de proteção social voltada aos trabalhadores contribuintes, como uma reposição de renda em períodos de inatividade do trabalhador, influenciada pela lógica do seguro ${ }^{8}$ e por isso também possui um período de carência, segundo os arts. 24 a 27, da Lei $\mathrm{n}^{\text {o }} 8.213$, de 24 de julho de 1991 (BRASIL, 1991). Dessa forma, contém ainda elementos do que Santos (1994) caracterizou como cidadania regulada, ou seja, um momento em que o Estado brasileiro não reconhecia os direitos sociais como inerentes ao ser social, mas apenas um reconhecimento normativo para os trabalhadores que possuíam sua inserção laboral mediada por regulamentação da profissão, da carteira assinada e de sindicato público.

Segundo Gentil (2006), com a CF 1988, a Previdência incluiu a contribuição Estatal e ampliou sua cobertura, abrangendo os trabalhadores rurais, assim como também, constituiu um piso básico aos benefícios, não inferior ao salário mínimo. Para a autora, com a CF 1988, alterou-se o conceito de seguro para a seguridade social, como um direito social em que cada um recebe a partir de suas necessidades (GENTIL, 2006).

Sem dúvidas a Carta Magna contém avanços conceituais importantes e elaborados em um momento essencial das lutas de classes, em que haviam despontados inúmeros levantes sociais que demandavam a redemocratização, a constituição de direitos sociais universais, entre outros. No entanto, o contexto histórico internacional do final da década de 1980 e início dos anos 1990 era de desmonte do Welfare State nos países em que esse padrão de regulamentação estatal vigorou e de adoção das políticas neoliberais; assim, compreende-se que o texto Constitucional incorporou diversas demandas das classes trabalhadoras, ao mesmo tempo em que se firmava no Brasil a mercantilização dos serviços sociais, incluindo a seguridade social.

A experiência de Welfare State vivenciada a partir dos anos 1940 nos países de capitalismo central, como Inglaterra, França e Estados Unidos (EUA), pode ser caracterizada, segundo Mishra (1995), pela intervenção do Estado para garantia do pleno emprego (padrão keynesiano-fordista), cobertura universal de serviços sociais 
(incluindo a universalização do sistema previdenciário) e garantia de renda mínima a todos os cidadãos como direito à proteção social.

Esse período, conhecido como os anos gloriosos do capitalismo de 1945 a 1975, correspondeu a um determinando momento de acumulação, em que cabia ao Estado auxiliar na redução do tempo de trabalho necessário por meio de mecanismos externos a condição salarial, os serviços sociais, permitindo ao capital, simultaneamente, o aumento da produtividade do trabalho e a ampliação do mercado consumidor interno, inclusive com o auxílio do endividamento dos trabalhadores ${ }^{9}$ para o acesso aos bens supérfluos, estabelecendo um amplo sistema de crédito ao consumidor.

Ressalta-se a partir dos mecanismos de exploração enunciados por Marx (2008) e de superexploração descritos em Marini $(1990,1998)$, que, se por um lado, neste padrão de acumulação ocorreu, aparentemente, a incorporação de demandas dos trabalhadores, por outro lado, estas não alteraram os padrões estruturais da lei geral de acumulação capitalista; ao contrário, como dito, foi possível devido a um momento específico em que havia uma tensão ideológica oriunda das experiências socialistas ${ }^{10}$, aliado a funções estatais de devolução de uma diminuta parcela da mais-valia expropriada da força de trabalho, na forma de serviços sociais universais.

Os parâmetros da tese de Marini (1990) são imprescindíveis para analisar que quando o capital se reconfigura, também são alteradas as funções primordiais do Estado burguês. Seguindo esta lógica de reestruturação e expansão, o capital central expandiu para os países dependentes a venda de serviços de saúde, de educação e de previdência social entre outros, que passaram a ser consumidos pelas classes intermediárias e proprietárias, tencionando a universalização dos direitos sociais previstos na CF 1988.

Isto acontece porque não se alteraram as condições fundamentais de superexploração das classes trabalhadoras: para alguns trabalhadores diretamente ligados a setores essenciais à produção exportadora que utilizam tecnologia de etapas inferiores, destinam-se à Previdência Social; e para a grande maioria da força de trabalho, pelos critérios de restrição aos benefícios previdenciários, são fixados mecanismos rigorosos para o acesso a benefícios assistenciais e/ou programas de transferência (condicionada) de renda. 
A Tabela 2, abaixo, permite acompanhar a contribuição para a previdência social, extremamente baixa nos estados amazônicos, que são diretamente relacionados a superexploração da força de trabalho, que além de condições de ingresso ao trabalho sem a carteira assinada, ainda possuem baixas taxas de rendimento mensal, como visto na Tabela 1.

Tabela 2 - Contribuição para Previdência Social, em qualquer emprego, domésticos sem carteira assinada e demais trabalhadores sem carteira assinada, Amazônia, 2010

\begin{tabular}{|c|c|c|c|c|c|c|}
\hline \multirow{2}{*}{ Espacialidade } & \multicolumn{2}{|c|}{ Em qualquer trabalho (\%) } & \multicolumn{2}{|c|}{$\begin{array}{l}\text { Trabalhadores domésticos sem } \\
\text { Carteira assinada }(\%)\end{array}$} & \multicolumn{2}{|c|}{$\begin{array}{l}\text { Demais trabalhadores sem Carteira } \\
\text { assinada (\%) }\end{array}$} \\
\hline & Contribuintes & Não Contribuintes & Contribuintes & Não Contribuintes & Contribuintes & Não Contribuintes \\
\hline Acre & 47,04 & 52,96 & 2,84 & 97,16 & 11,50 & 88,50 \\
\hline Amapá & 50,09 & 49,91 & 2,33 & 97,67 & 11,84 & 88,16 \\
\hline Amazonas & 45,45 & 54,55 & 2,51 & 97,49 & 14,25 & 85,75 \\
\hline M Maranhão & 35,05 & 64,95 & 3,16 & 96,84 & 12,53 & 87,47 \\
\hline ָָָ Mato Grosso & 58,31 & 41,69 & 4,27 & 95,73 & 13,22 & 86,78 \\
\hline Ě Pará & 38,40 & 61,60 & 3,25 & 96,75 & 11,62 & 88,38 \\
\hline Rondônia & 51,15 & 48,85 & 3,67 & 96,33 & 9,27 & 90,73 \\
\hline Roraima & 49,74 & 50,26 & 3,33 & 96,67 & 16,40 & 83,60 \\
\hline Tocantins & 49,22 & 50,78 & 2,51 & 97,49 & 14,07 & 85,93 \\
\hline
\end{tabular}

Fonte: Elaborada pelo autor, a partir de IBGE (2011).

De forma sintética, na Tabela 2, tem-se que: 1) mesmo considerando todas as formas de inserção trabalhista (com e sem carteira de trabalho assinada), estados como Maranhão (64\%), Pará (61\%), Amazonas (54\%) e Acre (52\%) possuem uma imensa parcela da população trabalhadora que não contribui com o regime de previdência social; 2) a força de trabalho dos domésticos possui uma remuneração tão aviltante que, em todos os estados, mais de $95 \%$ da categoria profissional não contribuem para a Previdência Social e; 3) considerando apenas os trabalhadores sem carteira assinada (exceto os domésticos), observa-se que, na Amazônia, mais de $85 \%$ se encontram na mesma situação.

Quando se analisa o conjunto da força de trabalho, tem-se uma grande parcela que não possui a garantia presente de sua reprodução orgânica, nem a projeção de previdência social contributiva. Desta forma, essa parcela recorre a programas de transferência (condicionada) de renda, de caráter não contributivo.

Com a Tabela 3, verifica-se a proporção de famílias que possuem um cadastro válido no Cadastro Único ${ }^{11}$ (CadÚnico) em relação ao número total de famílias de cada estado, além do percentual de famílias beneficiárias do Programa Bolsa Família ${ }^{12}$ (PBF) e o número de idosos beneficiários do Benefício de Prestação Continuada ${ }^{13}$ (BPC). 
SUPEREXPLORAÇÃO DA FORÇA DE TRABALHO E PREVIDÊNCIA SOCIAL NA AMAZÔNIA

Tabela 3 - Famílias cadastradas no CadÚnico e beneficiárias do PBF e idosos beneficiários do BPC Idoso, 2010

\begin{tabular}{c|c|c|c}
\multicolumn{5}{c}{$\begin{array}{c}\text { do PBF e idosos beneficiários do BPC Idoso, } 2010 \\
\text { Espacialidade }\end{array}$} & $\begin{array}{c}\text { \% de Famílias } \\
\text { beneficiárias do PBF em } \\
\text { relação ao total de } \\
\text { famílias }\end{array}$ & $\begin{array}{c}\text { \% de famílias com } \\
\text { cadastros válidos no } \\
\text { CadÚnico em relação ao ao } \\
\text { total de familias }\end{array}$ & $\begin{array}{c}\text { \% de pessoas } \\
\text { beneficiárias BPC Idoso } \\
\text { em relação ao total de } \\
\text { pessoas de 65 anos ou } \\
\text { mais de idade }\end{array}$ \\
\hline Acre & 31,98 & 49,04 & 8,23 \\
Amapá & 26,23 & 41,10 & 36,33 \\
Amazonas & 33,00 & 44,36 & 30,79 \\
\& Maranhão & 51,28 & 65,34 & 22,24 \\
Mato Grosso & 19,72 & 32,52 & 23,23 \\
Eará & 35,04 & 46,66 & 17,37 \\
Rondônia & 26,05 & 38,94 & 19,64 \\
Roraima & 40,96 & 57,70 & 5,61 \\
Tocantins & 34,51 & 52,60 & 20,36 \\
\hline
\end{tabular}

Fonte: Elaborada pelo autor, a partir de IBGE (2011).

Na Tabela 3, observa-se a elevada proporção de famílias beneficiárias do PBF em relação ao total de famílias que, em geral, é acima de 19\%, mas o estado do Maranhão (51\%), Roraima (40\%) e Pará (35\%) são os mais acentuados. Este percentual demonstra apenas as famílias que recebem o PBF, por isso o percentual de famílias cadastradas no CadÚnico é relevante na medida em que ele dimensiona as famílias com renda mensal por pessoa de até $1 / 2$ (meio) salário mínimo. Tem-se que no Maranhão (65\%), em Roraima (57\%) e no Tocantins $(52 \%)$ mais da metade de todas as famílias possuem o perfil CadÚnico.

Com relação à fração de pessoas idosas que recebem o BPC, destacam-se os estados do Amapá (36\%), Amazonas (30\%) e Mato Grosso (23\%), com um elevado número dessas pessoas, com renda mensal de até $1 / 4$ (um quarto) de salário mínimo.

Cabe ressaltar, que concordamos com as teses de autores como Gentil (2006) e Salvador (2008), que afirmam respectivamente, que 1) o "déficit" previdenciário de saldo negativo é enganoso e alarmista, pois não utiliza o cálculo de todas as receitas que devem ser alocadas à Previdência Social, de acordo com os art. 194 e 195 da CF 1988, que trata do orçamento da Seguridade Social ${ }^{14}$, desconsiderando as receitas oriundas da Contribuição para o Financiamento da Seguridade Social (COFINS), Contribuição Provisória sobre a Movimentação Financeira (CPMF) $)^{15}$, Contribuição Social sobre o Lucro Líquido (CSLL) e receitas de concursos de prognóstico e; 2) o fundo público exerce uma função ativa nas políticas macroeconômicas, sendo financiadores de políticas anticíclicas e fonte de recursos destinados a infraestruturas, transportes, pesquisas, subsídios de renúncias fiscais, transferências de recursos para juros e amortização 
da dívida pública, além de viabilizar a reprodução da força de trabalho.

A Tabela 4, a seguir, demonstra a importância dos estudos de Salvador (2008) e Gentil (2006) para entender o orçamento público e cálculos previdenciários, que devolvem ao eixo da luta da classe trabalhadora para decidir sobre a aplicação das receitas da seguridade social para propiciar o financiamento de políticas de proteção social universais.

Tabela 4 - Distribuição percentual das fontes de recursos (20002007) e aplicação das receitas da seguridade social (2005)

\begin{tabular}{|c|c|c|c|c|c|c|c|c|}
\hline \multicolumn{9}{|c|}{ ador (2008): Distribuição percentual das fortes de recurs os 2000-2007 } \\
\hline \multicolumn{5}{|c|}{ Fontes } & $2000(\%)$ & $2007(\%)$ & $\begin{array}{c}\text { Média sobre } \\
\text { total (\%) }\end{array}$ & $\begin{array}{l}\text { Variaç̃̃o 2000/ } \\
2007(\%)\end{array}$ \\
\hline \multirow{2}{*}{\multicolumn{5}{|c|}{$\begin{array}{l}1 \text { Impostos } \\
2 \text { Contribuicões Sociais }\end{array}$}} & 3,70 & 4,85 & 8.47 & 30.96 \\
\hline & & & & & 91,05 & 90.89 & 90,10 & $-0,17$ \\
\hline \multicolumn{5}{|c|}{ 21 Contribuições Empreg e Trab. Seguridade Social } & 47.53 & 44.45 & 45,52 & $-6,47$ \\
\hline \multirow{2}{*}{\multicolumn{5}{|c|}{$\begin{array}{l}\text { 2.1.2 Empregadores (P) } \\
\text { 2.1.3 Trabalhadores (PF) }\end{array}$}} & 30,74 & 28.49 & 28,96 & $-7,31$ \\
\hline & 13,19 & 13.16 & 12,85 & 3,14 \\
\hline & & & & & 6.12 & 8,15 & 6.88 & 33,10 \\
\hline \multicolumn{5}{|c|}{2.3 COFINS } & 25,33 & 24,93 & 28.28 & $-1,58$ \\
\hline & 1.95 & 5.47 & 3,14 & 179,99 \\
\hline \multicolumn{5}{|c|}{$\begin{array}{l}\text { 2.4Plano Segurid do Servidor } \\
2.5 \text { Custeio Pensão Militares }\end{array}$} & & & & \\
\hline \multicolumn{5}{|c|}{$\begin{array}{l}\text { 2.5 Custeio Pensão Militares } \\
2.6 \text { CPMF }\end{array}$} & 10,11 & 7.48 & 8.08 & $-28,00$ \\
\hline \multicolumn{5}{|c|}{$\begin{array}{l}2.6 \text { CPMF } \\
27 \text { Loterias }\end{array}$} & 0.00 & 0.03 & 0.02 & \\
\hline \multicolumn{5}{|c|}{$\begin{array}{l}27 \text { Loterias } \\
3 \text { Outras Fontes }\end{array}$} & 5,25 & 1.29 & 1.91 & $-75,44$ \\
\hline \multicolumn{5}{|c|}{4 Fundo Comb Errad Pobreza } & 0.00 & 2,97 & 1,54 & \\
\hline \multirow{2}{*}{\multicolumn{5}{|c|}{ Total (\%) }} & 100,00 & 100,00 & & \\
\hline \multirow{2}{*}{\multicolumn{5}{|c|}{$\begin{array}{l}\text { Total em R\$ milhões correntes } \\
\text { Total em R\$ milhöes con stan tes (IGP-DI) }\end{array}$}} & 118.119,28 & $304.800,84$ & $202.894,97$ & $158,04 \%$ \\
\hline & & & & & $256.163,64$ & $320.289,91$ & $276.161,50$ & $25,03 \%$ \\
\hline \multicolumn{9}{|c|}{ Gentil (2006): Aplicação das receitas da seguridade social, 2005} \\
\hline Receitas & $\begin{array}{c}\text { Total da } \\
\text { receita } \\
\text { arrecadada }\end{array}$ & $\begin{array}{l}\text { Aplicada na } \\
\text { seguridade } \\
\text { social }\end{array}$ & DRU $(20 \%)$ & RPPS $^{1}$ & $\begin{array}{l}\text { Divida } \\
\text { Judicial }^{2}\end{array}$ & $\begin{array}{l}\text { Outros } \\
\text { Ministérios }\end{array}$ & Subtotal & $\begin{array}{l}\text { Sem } \\
\text { identificação } \\
\text { de aplic ação }\end{array}$ \\
\hline COFINS & 87.902 & 39.033 & 17.580 & 24.520 & 3.386 & & 45.494 & 3.374 \\
\hline CPMF & 29.230 & 16.740 & 5.846 & 0 & 97 & 0 & 5.943 & 6.548 \\
\hline CSL & 26.323 & 16.394 & 5.265 & 9 & 113 & 0 & 5.387 & 4.542 \\
\hline Total & 143.455 & 72.167 & 28.691 & 24.529 & 3.596 & 8 & 56.824 & 14.464 \\
\hline
\end{tabular}

(1) Pagamento de aposentadorias e pensôes de servidores civis, militares; Indenizaçỏes a anistiados polificos.

(2) Pagamento de débitos judicia is periodicos e sentenças jud iciais transita das em julgado (preca tórios) devidas pela União, Autarquias, Fundaçôes, Empresas Públicas e Sociedades de E conomia Mista.

Receita arre cadad a cuja aplicação não consta nos demonstrativos de Execu ção Orçamentária por Fonte de Receita

Fonte: SALVADOR, E. da S. Fundo público no Brasil: financiamento e destino dos recursos da seguridade social (2000-2007). 2008. 395 f. Tese (Doutorado em Política Social) - Programa de Pós-Graduação em Política Social, Universidade de Brasília, Brasília, DF, 2008; GENTIL, Denise Lobato. A política fiscal e a falsa crise da seguridade social brasileira: análise financeira do período de 1990-2005. 2006. 358 f. Tese (Doutorado em Economia) - Instituto de Economia, Universidade Federal do Rio de Janeiro, Rio de Janeiro, 2006.

Tanto a contribuição dos autores Gentil (2006) e Salvador (2008) devem ser disseminadas, como o próprio processo de organização da classe trabalhadora é indispensável para a ampliação dos direitos sociais, incluindo a Previdência Social. No entanto, se há clareza sobre as delimitações estruturais do processo de exploração e superexploração da força trabalhadora, nos países centrais, a pro- 
teção social oriunda do padrão keynesiano-fordista representou um aumento da produtividade e da taxa de mais-valia.

Nos países dependentes, como não há necessidade de reduzir o valor real da força de trabalho, o capital não prescinde da instituição de um pacto de proteção social universal, o que torna mais essencial a adesão da classe trabalhadora nas lutas em torno da reivindicação dos direitos sociais, mas também torna as conquistas trabalhistas mais instáveis que nos países centrais.

Esta análise deve imprimir o reforço de que as lutas da classe trabalhadora pela proteção social universal são instrumentos imprescindíveis de organização, de fortalecimento de estratégias e projetos comuns, de acesso a melhores condições de reprodução, de acúmulo de conhecimentos, entre outros, mas são restringidos pela sociabilidade burguesa e, por isso, devem ser considerados apenas como um meio (que não deve ser subestimado), para o direcionamento necessário da classe trabalhadora na luta pela emancipação humana, obtida a partir da superação das relações de exploração e de superexploração.

\section{CONCLUSÃO}

O entendimento acerca da situação de exploração da força de trabalho sob o capital nos revela um condicionante estrutural que permeia a sociabilidade capitalista. A tendência à autoexpansão e autovalorização do capital cria os mecanismos de dependência, sustentados pela superexploração da força de trabalho.

$\mathrm{Na}$ Amazônia brasileira, devido sua singularidade histórica de subordinação a essa lógica no interior do capital dependente, agravam-se as situações de superexploração da força do trabalho, além de criar uma inumerável superpopulação relativa, gerando uma pauperização acentuada das classes trabalhadoras amazônicas, que não conseguem acessar as políticas previdenciárias e, portanto, não têm atendidas suas necessidades de sobrevivência em períodos de interrupção de sua capacidade laborativa.

Refere-se a uma população trabalhadora que se submeteu às piores formas de aviltamento de sua força de trabalho, que a degradou precocemente e que nunca conseguiu suprir suas necessidades sociais básicas, na totalidade. E quando vivencia a interrupção tem- 
porária ou definitiva de sua força de trabalho não é amparada pelo sistema previdenciário público.

As alternativas para essa parcela da população trabalhadora são: 1) acessar o sistema previdenciário privado, mas como visto, acima, essa possibilidade é reduzida para a Amazônia, pois grande parte dos trabalhadores possui baixos rendimentos mensais; 2) recorrer a programas de transferência de renda, cada vez mais focalizados e restritivos, que não garantem o direito de quem dele necessita; 3) depender financeiramente de algum membro familiar, inclusive auxiliando-o sem remuneração no trabalho daquele e; 4) vivenciar a pauperização absoluta.

Finalmente, compreende-se que as lutas pela consolidação e ampliação da proteção social e, também, em torno da Previdência Social, são fundamentais para as conquistas dos direitos sociais da classe trabalhadora, porque significam uma restituição de parcela da mais-valia. Mas a história já demonstrou que mecanismos de acumulação de capital podem inserir algumas demandas da classe trabalhadora, como nos períodos dos anos gloriosos, mas estes não são definitivos e, de forma alguma, visam eliminar a exploração e a superexploração da força de trabalho.

Por isso, superar o modo de produção capitalista é uma necessidade categórica da classe trabalhadora, incluindo a dos países dependentes e, especialmente, na Amazônia, onde suas condições de reprodução são extremamente débeis.

\section{REFERÊNCIAS}

BRASIL. Constituição da República Federativa do Brasil: texto constitucional promulgado em 5 de outubro de 1988, com as alterações adotadas pelas Emendas constitucionais nos 1/1992 a 90/2015, pelo Decreto legislativo no 186/2008 e pelas Emendas constitucionais de revisão nos 1 a 6/1994. 48. ed. Brasília, DF: Câmara dos Deputados, Edições Câmara, 2015. (Série textos básicos, n. 119).

. Presidência da República. Lei no 8.213, de 24 de julho de 1991. Dispõe sobre os Planos de benefícios da Previdência Social e dá outras providências. Diário Oficial da União, Brasília, DF, 1991.

GENTIL, Denise Lobato. A política fiscal e a falsa crise da seguridade social brasileira: análise financeira do período de 1990-2005. 2006. 
$358 \mathrm{f}$. Tese (Doutorado em Economia) - Instituto de Economia, Universidade Federal do Rio de Janeiro, Rio de Janeiro, 2006.

CONFEDERAÇÃO NACIONAL DA INDÚSTRIA. Perfil da indústria nos estados 2014. Brasília, DF, 2014.

INSTITUTO BRASILEIRO DE GEOGRAFIA E ESTATÍSTICA. Censo 2010. Rio de Janeio, 2011.

MARINI, R. M. Dialéctica de la Dependencia. México: Ediciones Era, 1990.

Duas notas sobre o socialismo. Tradução de Ilse Gomes Silva, Jair Pinheiro e Lúcio Flávio de Almeida. Lutas sociais, São Paulo, n. 5, p. 107-123, 1998.

MARX, Karl. O Capital: crítica da economia política. Tradução de Reginaldo Sant'Anna. 25. ed. Rio de Janeiro: Civilização Brasileira, 2008. Livro I, v. 1 e 2.

MISHRA, R. O Estado-Providência na sociedade capitalista: estudo comparativo das políticas públicas na Europa, América do Norte e Austrália. Oeiras/Portugal: Celta, 1995.

SALVADOR, E. da S. Fundo público no Brasil: financiamento e destino dos recursos da seguridade social (2000-2007). 2008. $395 \mathrm{f}$. Tese (Doutorado em Política Social) - Programa de Pós-Graduação em Política Social, Universidade de Brasília, Brasília, DF, 2008.

SANTOS, W. G. dos. Cidadania e justiça: a política social na ordem brasileira. 3. ed. Rio de Janeiro: Campus, 1994.

SILVA, C. P. Marx e o imperativo da mais-valia. 2010. $92 \mathrm{f}$. Dissertação (Mestrado em Serviço Social) - Programa de Pósgraduação em Serviço Social, Universidade Federal do Pará, Belém, 2010.

\section{NOTAS:}

1 De acordo com Marx (2008), o tempo necessário à reprodução da força de trabalho (seu valor) corresponde ao valor dos meios de subsistência necessários à manutenção da vida do trabalhador, como por exemplo a alimentação, o vestuário, a moradia entre outros.

2 Sobre a determinação da taxa de mais-valia, Marini (1990) explica que ela não se constitui, necessariamente, a partir da maior produtividade da força de trabalho. Isto porque o aumento da massa de produtos durante a jornada não significa o incremento de mais valor, pois o valor social destes produtos será reduzido na mesma proporcionalidade da produtividade da força de trabalho. Assim, o que de fato, determina a taxa de mais-valia é o grau de exploração da força de trabalho e o aumento da produtividade, uma consequência. 
3 Marx (2008) explica que enquanto a mais-valia é uma consequência da mudança de valor resultante do capital variável (v) e determinada pela parte excedente da jornada de trabalho; a taxa de mais-valia refere-se a valorização proporcional do capital variável (grandeza proporcional de mais-valia), expressa em $\mathrm{m} / \mathrm{v}$, portanto, revela o grau exato de exploração da força de trabalho pelo capital.

4 Marini (1990) refere que estes meios de subsistência, anteriormente produzidos diretamente pelos próprios trabalhadores, são incorporados ao capital, na forma do capital variável, restituídos ao trabalhador por meio do salário.

5 A Região Amazônica aqui enfatizada, envolve apenas os estados brasileiros pertencentes à Bacia Amazônica e com área de vegetação típica, ou seja, são os sete estados da Região Norte, Acre, Amapá, Amazonas, Pará, Rondônia, Roraima e Tocantins, além de parte dos Estados Maranhão e Mato Grosso.

6 Para Marx (2008), a composição orgânica do capital, expressa-se no valor, mas é determinada pela composição técnica, que é a relação entre capital constante (meios de produção: matéria-prima, matérias auxiliares e meios de trabalho) e capital variável (força de trabalho), ou seja, o processo produtivo. $\mathrm{O}$ acréscimo de produtividade refere-se a um aumento da massa de meios de produção transformados no ato do trabalho, pela força de trabalho, que resulta na redução do capital variável, isto é, da força de trabalho, conduzindo a constituição de uma superpopulação relativa.

7 No ano de 2010, o salário mínimo correspondia a $\mathrm{R} \$ 510,00$ (quinhentos e dez reais).

8 Gentil (2006) explica que o conceito de seguro refere-se a um contrato individual que estabelece um direito pessoal ao contribuinte ou filiado.

9 Possível em virtude do padrão protetivo do próprio Welfare State.

${ }^{10}$ Refere-se aqui às experiências do Leste Europeu e Cuba, pois trata-se de tentativas de revoluções socialistas, que tencionaram a hegemonia capitalista. No entanto, não abordaremos a discussão sobre o socialismo real, que trata da etapa de transição para uma sociabilidade mais desenvolvida e que restitui o trabalhador ao comando, concepção e apropriação do resultado do seu trabalho.

${ }^{11}$ Instituído pelo Decreto $\mathrm{n}^{\circ} 3.877$, de 24 de julho de 2001, possui o objetivo de identificar as famílias com renda mensal de até meio salário mínimo por pessoa para planejamento de políticas públicas.

${ }^{12}$ O PBF foi criado pela Lei $n^{\circ} 10.836$, de 9 de janeiro de 2004, que visou unificar a gestão e a execução dos programas de transferência de renda. O PBF utiliza o CadÚnico para a concessão de benefícios e possui como critérios de inserção: 1) famílias com renda por pessoa de até R\$77,00 mensais e 2) famílias com renda por pessoa entre R\$77,01 e R\$ 154,00 mensais, desde que tenham, em sua composição, crianças ou adolescentes de 0 a 17 anos. Além disso possui condicionalidades para a permanência das famílias: a) na área da educação, crianças e adolescentes entre 6 a 15 anos de idade, devem possuir frequência escolar de $85 \%$ e adolescentes entre 16 e 17 anos, frequência de $75 \%$; b) na área da saúde, gestantes devem fazer pré-natal e ir as consultas na Unidade de Saúde e, para as crianças de até 7 anos de idade, devem ter todas as vacinas recomendas, além de medir, pesar, acompanhar o crescimento e o desenvolvimento.

${ }^{13}$ O BPC é uma transferência de renda sem condicionalidades e independente de contribuição prévia para a previdência para idosos com 65 anos ou mais com renda familiar por pessoa 


\section{SUPEREXPLORAÇÃO DA FORÇA DE TRABALHO E PREVIDÊNCIA SOCIAL}

\section{NAAMAZÔNIA}

abaixo de $1 / 4$ (um quarto) do salário mínimo, instituído pela Lei ${ }^{\circ} 8.742$, de 7 de dezembro de 1993

${ }^{14}$ O conjunto das receitas previstas nos dois Artigos envolve: 1) Contribuições Previdenciárias ao INSS; 2) Programa de Integração Social (PIS) e Programa de Formação do Patrimônio do Servidor Público (PASEP), 3) Contribuição Social sobre o Lucro Líquido (CSLL); 4) Contribuição para o Financiamento da Seguridade Social (COFINS); 5) Receitas recolhidas aos Órgãos da Seguridade Social; 6) Transferência do Orçamento Fiscal para os Encargos Previdenciários da União (EPU). As receitas destinadas ao financiamento da Seguridade Social, mesmo quando vinculadas a uma atividade estatal específica, não é realizada pela descentralização da aplicação de recursos; assim, mesmo que as ações governamentais sejam descentralizadas, somente a União é detentora do crédito orçamentário.

${ }^{15}$ A CPMF foi criada em 13 de julho de 1993, durante o governo de Itamar Franco e foi extinta em 13 de dezembro de 2007 Durante o período de vigência de 1993-2007, a CPMF arrecadou R\$ 223 bilhões. 
